\title{
IDENTIFIKASI HAZARD PADA PEKERJA KONTRAKTOR SIPIL DENGAN METODE CSMS DI PT. X PASURUAN
}

\author{
Tanti Olivina Sari \\ PT. Multi Makmur Mubarok \\ Surabaya, Provinsi Jawa Timur, Indonesia \\ Email: tantiolivina@yahoo.com
}

\begin{abstract}
Hazard is always available on every work process in the workplace and each hazard has a different level of potential hazard, and therefore needs to be done identification hazard. Contractor Safety Management System (CSMS) Program in PT. X applied to prevent and suppress the occurrence of a hazard to the civilian contractors. This study was conducted to identify the hazard to workers civilian contractors using CSMS PT. X Pasuruan. This research was an observational descriptive and presented in the narrative. Identification of hazard in stage are pre-work activities and execution of work at civilian contractor PT. X Pasuruan. The data collection method was by observation, indepth interview, and interviews. The results showed on the stage of pre-employment activities PT.1 as a civilian contractor company in cooperation with PT. X Pasuruan, meets only 14 subjects (93.3\%). At the stage of implementation of the work there are two items that realization is not achieved, and at the final evaluation stage there are three items that are below $80 \%$ votes and does not meet the requirements. Risk of harm to the contractor civilians in the workplace can be prevented to a minimum, it was because a good management system in the company. Companies obedient in carrying CSMS program regulating health and safety management systems of work, by making the program a monitoring schedule for the work progresses and increasing Awareness to contractors, by providing training in occupational health and safety aspects.
\end{abstract}

Keywords: identification, potential hazard

\begin{abstract}
ABSTRAK
Bahaya selalu ada di tempat pada setiap proses pekerjaan di tempat kerja dan masing-masing bahaya memiliki tingkat potensi bahaya yang berbeda, oleh sebab itu perlu dilakukan identifikasi bahaya. Program Contractor Safety Management System (CSMS) di PT. X diterapkan untuk mencegah dan menekan terjadinya bahaya kecelakaan pada kontraktor sipil. Tujuan penelitian ini adalah untuk mengidentifikasi hazard pada pekerja kontraktor sipil dengan menggunakan metode CSMS di PT. X Pasuruan. Penelitian ini bersifat deskriptif observasional dan disajikan dalam bentuk narasi. Identifikasi hazard meliputi kegiatan pra-pekerjaan dan pelaksanaan pekerjaan pada kontraktor sipil PT. X Pasuruan. Metode pengambilan data yaitu dengan melakukan observasi, indepth interview, dan wawancara. Hasil penelitian menunjukkan pada tahapan kegiatan pra-pekerjaan PT.1 sebagai perusahaan kontraktor sipil yang bekerja sama dengan PT. X Pasuruan, hanya memenuhi 14 pokok bahasan $(93,3 \%)$. Pada tahapan pelaksanaan pekerjaan terdapat 2 item yang realisasinya tidak tercapai. Risiko bahaya pada kontraktor/subkontraktor sipil di tempat kerjanya dapat dicegah seminimal mungkin, hal ini karena terdapat sistem manajemen yang baik pada perusahaan. Perusahaan patuh dalam menjalankan program CSMS yang mengatur tentang sistem manajemen kesehatan dan keselamatan kerja, dengan membuat program jadwal monitoring selama pekerjaan berlangsung dan meningkatkan awareness kepada para kontraktor, dengan memberi pelatihan-pelatihan dalam aspek kesehatan dan keselamatan kerja.
\end{abstract}

Kata kunci: identifikasi, potensi bahaya

\section{PENDAHULUAN}

Berkembangnya industri pada dunia kerja yang selalu dihadapkan dengan tantangan-tantangan baru dan bahaya yang dapat terjadi, dimana tantangan dan bahaya tersebut harus dapat dicegah dan diatasi dengan segera bila perusahaan masih ingin tetap berjalan. Masalah yang selalu timbul sejak awal dunia industri dimulai adalah adanya kecelakaan dan penyakit akibat kerja (Sucofindo, 2011).
Perusahaan yang menjalankan aktivitasnya saat ini bekerja sama dengan perusahaan kontraktor/ subkontraktor sebagai pelaksana pekerjaan yang diharapkan oleh perusahaan tersebut. Kontraktor/ subkontraktor ini diharapkan untuk dapat melakukan pekerjaannya dengan aman dilihat dari kesehatan dan keselamatan kerja, hal tersebut sangatlah penting karena kontraktor/subkontraktor dianggap sebagai mitra perusahaan dan masing-masing pekerjaan memiliki tingkat risiko yang berbeda antara satu 
dengan yang lainnya (Setyawan,1997). Perusahaan bertanggung jawab atas keselamatan dan kesehatan saat kontraktor/subkontraktor berada di tempat kerja mereka. Program yang digunakan sebagai upaya untuk menjaga keselamatan dan kesehatan kontraktor yang ada di perusahaan adalah dengan melalui Contractor Safely Management System (CSMS).

Bagi setiap perusahaan masalah kecelakaan dan penyakit akibat kerja dianggap sebagai masalah besar yang harus diperkecil kemungkinan terjadinya, karena kerugian yang timbul tidak hanya kerugian materi saja, tetapi juga dapat menimbulkan korban jiwa. Sumber daya manusia yang menjadi korban jiwa merupakan kerugian yang cukup besar bagi perusahaan, karena sumber daya manusia tidak dapat digantikan oleh teknologi apapun. Kerugian yang didapat langsung dari kecelakaan dan penyakit akibat kerja berupa biaya pengobatan dan kompensasi yang diberikan kepada korban oleh perusahaan, sedangkan kerugian tidak langsung dapat berupa kerusakan alatalat produksi, hilangnya waktu kerja para pekerja dan berhentinya proses produksi (Sahab, 1997).

Kecelakaan yang ada saat bekerja tidak terjadi begitu saja tanpa sebab yang ada, namun dapat dipengaruhi oleh beberapa faktor, yaitu manusia atau unsafe action, mesin, bahan baku dan lingkungan atau unsafe conditions (Ramli, 2009).

International Association Asia, Australia, dan Amerika memberikan catatan data incident dan accident dalam 100 juta pekerja, di mana dari 36 perusahaan yang ada di 60 negara di dunia menunjukkan bahwa angka kecelakaan kerja yang terjadi pada pekerja tetap di perusahaan lebih rendah dibandingkan dengan kontraktor yang bekerja pada perusahaan tersebut.

Di Indonesia angka kecelakaan kerja masih tinggi dan memprihatinkan. Terdapat 65.000 kasus kecelakaan kerja sepanjang tahun 2010, tercatat 1.965 orang pekerja yang meninggal, 3.662 pekerja yang mengalami cacat fungsi, 2.713 orang pekerja yang mengalami cacat sebagian, 31 orang pekerja yang mengalami cacat total dan sisanya dapat disembuhkan, namun jumlah itu masih tergolong tinggi (Jamsostek, 2012).

Data kecelakaan dan analisis risiko yang diperoleh dan telah dilaporkan diketahui bahwa yang terjadi pada setiap pekerjaan yang cukup tinggi terutama pada kontraktor/subkontraktor maka perlu adanya peraturan, standar dan code of practice yang disahkan oleh pemerintah dan lembaga ketenagakerjaan guna mencegah terjadinya kecelakaan pada kontraktor melalui program Contractor Safety Management System (CSMS). Contractor Safety Management System (CSMS) suatu program yang ada di setiap perusahaan yang ditujukan untuk kontraktor/subkontraktor dalam pelaksanaan pekerjaan, agar kontraktor/ subkontraktor dapat bekerja dengan aman sesuai aspek Keselamatan dan Kesehatan Kerja (K3) yang ada di perusahaan tempat mereka bekerja, hal ini seperti yang diungkapkan oleh Nitya (2010).

Usaha yang digunakan untuk mencegah terjadinya kecelakaan, yaitu diawali dengan menemukan faktor-faktor apa saja yang menjadi penyebab dasar terjadinya kecelakaan. Melalui tindakan preventif diharapkan lebih efektif dalam mencegah terjadinya kecelakaan kerja, karena pencegahan dapat dilakukan dari awal, sebelum dilakukan pekerjaan dan sebelum adanya kecelakaan kerja, sehingga dapat dikatakan bahwa upaya preventif yang dilakukan pada keselamatan kerja memiliki peran yang penting dalam proses produksi pada setiap perusahaan, supaya produktivitas perusahaan tersebut juga dapat meningkat hal ini juga sesuai dengan penelitian yang dilakukan oleh Lukiatsinto (2014). Inspeksi merupakan salah satu elemen Keselamatan dan Kesehatan Kerja yang dapat berguna sebagai tindakan preventif yang paling utama dalam menurunkan terjadinya angka kecelakaan kerja yang ada di perusahaan, dengan maksud dan tujuan di mana dilakukan inspeksi keselamatan kerja bukan hanya untuk mencari kesalahan saat bekerja, tetapi sebagai upaya untuk meyakinkan bahwa telah diterapkannya keselamatan kerja yang sesuai dengan peraturan dengan baik dan benar (Sugandi, 2003).

PT. X merupakan perusahaan ternama yang bergerak pada bidang air minum dalam kemasan, dimana PT. X ini dalam menjalankan aktivitasnya banyak menunjuk kontraktor/subkontraktor sipil sebagai rekanan guna melancarkan proses produksi. Berdasarkan Permenaker dalam klausul SMK3 di mana setiap perusahaan yang memiliki rekanan dengan kontraktor/subkontraktor bertanggung jawab atas pembinaan Keselamatan dan Kesehatan Kerja kontraktor/subkontraktor tersebut, oleh karena itu pemenuhan program CSMS pada kontraktor/subkontraktor yang ada di perusahaan harus dilakukan secara menyeluruh dan dalam pelaksanaannya juga dibutuhkan proses controlling guna memastikan program CSMS ini apakah berjalan sesuai dengan aturan yang telah ada. 
Data kecelakaan kerja yang didapatkannya itu terdapat total 11 kecelakaan kerja yang ada tahun 2015, di mana 1 orang pekerja jatuh dari ketinggian, 3 orang pekerja kejatuhan barang dari atas, 3 orang pekerja yang terkena benturan keras, 1 orang pekerja dengan kaki terkilir saat turun dari scaffolding, 2 orang pekerja yang terjepit, dan 1 orang pekerja yang terpeleset di lingkungan kerjanya. Berdasarkan permasalahan tersebut, maka peneliti tertarik untuk melakukan penelitian tentang identifikasi hazard pada pekerja kontraktor sipil dengan Metode CSMS di PT. X Pasuruan dengan tujuan untuk memenuhi Identifikasi hazard yang ada pada pekerja kontraktor sipil dengan metode CSMS di PT. X Pasuruan.

\section{METODE}

Penelitian ini dilakukan di PT. X Pasuruan. Penelitian ini dilakukan pada bulan Mei sampai dengan Desember 2016. Penelitian ini dilakukan dengan cara observasional, data yang terkumpul dianalisis secara deskriptif dan disajikan dalam bentuk narasi.

Jenis penelitian ini adalah observasional, metode yang digunakan dengan cara observasi dan wawancara langsung, hal ini dilakukan untuk mempelajari dan mengamati secara langsung proses pelaksanaan identifikasi hazard dengan menggunakan metode Contractor Safety Management System (CSMS). Mengidentifikasi potensi bahaya yang diterapkan oleh PT. X Pasuruan. Data primer didapatkan dengan cara melakukan observasi secara langsung tanpa sepengetahuan dari para pekerja dan wawancara menggunakan kuesioner yang ada dengan manajer dan supervisor PT. X Pasuruan, sedangkan untuk data sekunder didapatkan dari dokumen CSMS kontraktor sipil PT.1 di PT. X Pasuruan.

Informan dari penelitian ini adalah manajer dan supervisor PT. X Pasuruan. Cara yang digunakan untuk menentukan informan ini dilakukan dengan purposive sampling, karena diambil berdasarkan pada pertimbangan tertentu dengan menggunakan cirri-ciri dan sifat tertentu (Sugiyono, 2012). Data yang telah diambil kemudian dikumpulkan, diolah secara deskriptif dan disajikan dalam bentuk narasi, di mana dalam penelitian ini akan mendeskripsikan tentang identifikasi hazard pada pekerja kontraktor sipil dengan metode CSMS di PT.X Pasuruan.

\section{HASIL}

\section{Gambaran Umum Perusahaan}

PT. X Pasuruan adalah salah satu perusahaan air minum dalam kemasan terbesar di Jawa Timur, tidak hanya di Jawa Timur saja perusahaan ini juga menjadi perusahaan air minum dalam kemasan yang terbesar di wilayah Indonesia bagian Timur. Perusahaan ini memproduksi air minum dalam kemasan sebanyak 83 liter/detik. PT. X Pasuruan dalam memproduksi Air Minum Dalam Kemasan (AMDK) tetap menjaga kualitas dan keamanan bagi konsumen, karena dalam produksinya melalui proses yang ramah lingkungan dengan tetap memperhatikan upaya tindakan pencegahan pencemaran, mematuhi segala peraturan yang ada dan ditetapkan oleh pemerintah, selalu memperbaiki dan meningkatkan mutu beserta kualitas dari hasil produksi, tetap menjaga kehalalan hasil dari produksi, memperhatikan keamanan pangan dan kinerja lingkungan secara berkesinambungan dalam rangka memenuhi dan memuaskan kebutuhan serta harapan pelanggan yang dilihat dari segala elemen yang ada.

PT. X Pasuruan terletak di Jawa Timur, Pasuruan. PT. X memiliki luas daerah yaitu 8,2 $\mathrm{Ha}$, yang terdiri dari luas bangunan seluas $4,16 \mathrm{Ha}$ $(50,78 \%)$ dan area terbuka seluas $4,03 \mathrm{Ha}(49,21)$.

Visi PT. X Pasuruan adalah menjadi produsen air minum dalam kemasan 19 liter (jug) yang terkemuka di Indonesia terutama dalam aspek keselamatan, kualitas dan volume produksi.

Misi PT. X Pasuruan antara lain: Terpenuhinya semua harapan para pemangku kepentingan (stakeholder) yang ada melalui proses bisnis yang bersih (no fraud), ergonomis, berwawasan lingkungan yang luas dengan orientasi pada kualitas, kinerja ekonomi dan sosial, Penyediaan produk air minum dalam kemasan 19 liter yang terjamin tingkat keamanannya, berkualitas dan tersedia setiap waktu guna mencukupi kebutuhan rumah tangga dan perkantoran di seluruh Indonesia, Mendukung adanya program Indonesia sehat melalui program edukasi dan program penyediaan akses air bersih untuk masyarakat di Indonesia, Memberikan kontribusi yang nyata dengan tetap menjaga kelestarian lingkungan di daerah resapan lereng Gunung Bromo. 


\section{Gambaran Umum PT. 1}

PT. 1 adalah perusahaan swasta nasional yang bergerak dalam bidang Fabrication dan Engineering Procurement Construction Services. PT. 1 ini berada di daerah Gempol Pasuruan. PT. 1 dalam mencari sumber daya manusia di perusahaannya dengan melakukan seleksi pekerja dengan melihat kemampuan rekayasa design yang dimiliki oleh masing-masing individu. Sumber daya manusia yang dimiliki oleh PT.1 ini juga diambil dari proses seleksi yang ketat, di mana pada setiap pekerjanya harus memiliki sertifikat-sertifikat yang dapat menunjang produktivitasnya dalam melakukan pekerjaan terutama di bidang keselamatan dan kesehatan kerjanya, dengan sumber daya manusia yang dimiliki oleh PT.1 ini dapat mengembangkan usahanya guna untuk membuat perusahaan terus berkembang terutama dalam pembuatan alat-alat yang dibutuhkan oleh perusahaan-perusahaan rekanan PT. 1 dalam bidang apapun, hal ini dapat terlihat dari lingkup kerja yang semakin luas mulai dari rekayasa design, procurement, fabrikasi, instalasi dan konstruksi, testing dan commisioning.

\section{Hasil Identifikasi Hazard pada Pekerja Kontraktor Sipil dengan Metode CSMS di PT. X Pasuruan}

Penelitian yang dilakukan di PT. X Pasuruan ini adalah dengan mengidentifikasi hazard dengan metode CSMS (Contractor Safety Management System) terhadap pekerja kontraktor sipil rekanan PT. X Pasuruan.

Menurut Ramli (2010) hazard atau bahaya adalah suatu keadaan yang dapat berpotensi menimbulkan kecelakaan, cidera sampai dengan kematian, selain itu juga dapat menimbulkan kerusakan dan gangguan lainnya, oleh karena itu diperlukan suatu pengendalian terhadap bahaya tersebut supaya tidak menimbulkan kerugian yang besar.

PT. X Pasuruan mendefinisikan CSMS (Contractor Safety Management System) adalah suatu sistem manajemen yang dimiliki oleh perusahaan yang berguna dalam pengelolaan aspek keselamatan, kesehatan kerja dan lingkungan bagi para kontraktor yang sedang melakukan kerja sama dengan PT.X Pasuruan.

Kegiatan CSMS yang ada di PT.X Pasuruan ini melibatkan berbagai unit kerja dan fungsi dalam melakukan programnya, di mana setiap unit kerja dan fungsi mendapatkan bagian dan peran masingmasing dalam terlaksananya program ini. PT.X Pasuruan juga telah membuat bagan alur yang dapat berguna dalam pelaksanaan tahap kegiatan CSMS oleh tiap-tiap unit kerja atau fungsi agar program CSMS ini dapat berjalan dengan baik dan lancar sesuai dengan harapan.

Tahapan kegiatan pra-pekerjaan (pre-job activity) adalah suatu kegiatan yang dilakukan oleh perusahaan berupa kegiatan awal yang dilakukan oleh kontraktor/subkontraktor sebelum memulai suatu pekerjaan. Pada tahapan ini perusahaan memberikan kesempatan kepada kontraktor agar dapat lebih mengenal lingkungan kerja, peraturan dan kegiatan yang akan dilaksanakan selama kontrak yang telah disepakati oleh kedua belah pihak, serta dapat mengetahui kondisi lingkungan kerja dan interaksi dengan seluruh pekerja selama pekerjaan berlangsung. Berikut di bawah ini adalah Daftar Periksa Pra Pekerjaan (pre-job activity) yang ada di PT.X Pasuruan berdasarkan Tabel 1 diketahui bahwa PT. 1 kontraktor sipil rekanan PT. X Pasuruan. Pada tahapan pra pelaksanaan pekerjaan hanya dapat terpenuhi sebanyak 14 item $(93,3 \%)$ dan 1 item $(6,7 \%)$ yang tidak dapat terpenuhi.

Pelaksanaan pekerjaan (work in progress) adalah kegiatan yang dilakukan oleh kontraktor/ subkontraktor sesuai dengan kontrak yang telah disepakati oleh kedua belah pihak selama pekerjaan berlangsung terutama dalam pelaksanaan keselamatan dan kesehatan kerja. Kontraktor/ subkontraktor dalam hal ini harus melakukan sedini mungkin upaya identifikasi risiko bahaya guna mencegah kecelakaan kerja apa saja yang dapat terjadi pada saat bekerja sesuai dengan sifat dan jenis bahaya yang ada di sekitar tempat kerja. Pelaksanaan pemenuhan program CSMS pada kontraktor/subkontraktor yang ada di perusahaan harus dilakukan secara menyeluruh dan dalam pelaksanaannya juga dibutuhkan proses controlling guna memastikan program CSMS ini apakah berjalan sesuai dengan aturan yang telah ada.

Berdasarkan Tabel 2 penilaian pelaksanaan pekerjaan terdapat 2 item yang dianggap tidak mencapai target sesuai dengan harapan, yaitu pada keselamatan dan kesehatan kerja poin alat pelindung diri (APD) dan pada poin keselamatan pengelasan, dengan demikian PT.1 mendapatkan nilai buruk. 
Tahapan evaluasi akhir ini digunakan sebagai umpan balik kepada tim manajemen perusahaan. Bagi kontraktor/subkontraktor penilaian ini dapat menjadi bahan untuk improvement penerapan sistem keselamatan dan kesehatan kerja lindung lingkungan yang dimiliki, dan untuk perusahaan yang memberikan pekerjaan, penilaian ini akan dimasukkan ke dalam data bank perusahaan. Pada kontraktor/subkontraktor yang memiliki evaluasi akhir baik, perusahaan akan memberikan kesempatan kembali untuk kontraktor/subkontraktor mengikuti tender berikutnya dengan jenis pekerjaan yang sama.

Tabel 1. Hasil Identifikasi Hazard pada Kontraktor Sipil tahapan Pra Pekerjaan (pre-job activity)

\begin{tabular}{|c|c|c|}
\hline Pokok Bahasan & Ya & Tidak \\
\hline Apakah kontraktor sudah memahami sistem manajemen SHE PT X? & $\sqrt{ }$ & \\
\hline Apakah semua program dan prosedur sudah disetujui oleh PT X? & $\sqrt{ }$ & \\
\hline Apakah SHE plan sudah di review dan ditandatangani? & $\sqrt{ }$ & \\
\hline Apakah semua peralatan yang akan digunakan sudah lulus inspeksi PT X? & $\sqrt{ }$ & \\
\hline $\begin{array}{l}\text { Apakah semua aktivitas kritis yang akan berdampak negatif pada aspek SHE telah didiskusikan } \\
\text { dan dianalisis bersama oleh PT X? }\end{array}$ & $\sqrt{ }$ & \\
\hline Apakah semua lay out peralatan telah disetujui PT X? & $\sqrt{ }$ & \\
\hline Apakah selama pekerjaan berlangsung kontraktor menempatkan tenaga yang ahli di bidang SHE? & $\sqrt{ }$ & \\
\hline $\begin{array}{l}\text { Apakah selalu dilakukan } S H E \text { meeting sebelum pekerjaan dimulai dan dihadiri oleh semua } \\
\text { pekerja? }\end{array}$ & $\sqrt{ }$ & \\
\hline $\begin{array}{l}\text { Apakah setiap pekerja kontraktor sudah memahami peran masing-masing dalam menghadapi } \\
\text { keadaan darurat? }\end{array}$ & & $\sqrt{ }$ \\
\hline $\begin{array}{l}\text { Apakah semua sarana dan prasarana untuk menunjang kondisi darurat telah disiapkan dan } \\
\text { diperiksa kelayakannya? }\end{array}$ & $\sqrt{ }$ & \\
\hline Apakah semua pekerja telah memahami sistem alarm tanda bahaya? & $\sqrt{ }$ & \\
\hline $\begin{array}{l}\text { Apakah tersedia prosedur untuk mencegah dan menanggulangi risiko Bahan Berbahaya dan } \\
\text { Beracun? }\end{array}$ & $\sqrt{ }$ & \\
\hline Apakah tersedia prosedur untuk mencegah dan menanggulangi risiko bahan-bahan kimia? & $\sqrt{ }$ & \\
\hline $\begin{array}{l}\text { Apakah tersedia prosedur untuk mencegah dan menanggulangi risiko material mudah meledak } \\
\text { dan terbakar? }\end{array}$ & $\sqrt{ }$ & \\
\hline Apakah tersedia prosedur untuk mencegah dan menanggulangi risiko kegagalan peralatan? & $\sqrt{ }$ & \\
\hline Total & 14 & 1 \\
\hline$\%$ & $93,3 \%$ & $6,7 \%$ \\
\hline
\end{tabular}

Tabel 2. Hasil Identifikasi Hazard pada Pekerja Kontraktor Sipil Tahap Penilaian Pelaksanaan Pekerjaan

\begin{tabular}{lcc}
\hline \multicolumn{1}{c}{ Kegiatan } & PT.1 & Tealisasi \\
\hline Lingkungan & & \\
\hline Kerapihan dan kebersihan & 7 & 10 \\
\hline Keselamatan dan Kesehatan Kerja & & 6 \\
\hline Alat pelindung diri (APD) & 7 & 10 \\
\hline Pencegahan dan perlindungan kebakaran & 7 & 10 \\
\hline Penandaan dan barikade & 7 & 10 \\
\hline Keselamatan kelistrikan & 7 & 10 \\
\hline Keselamatan tabung gas bertekanan & 4 & 3 \\
\hline Keselamatan pengelasan & 4 & 10 \\
\hline Bekerja di ketinggian & 8 & \\
\hline
\end{tabular}


Tabel 3. Hasil Identifikasi Hazard Pada Pekerja Kontraktor Sipil Tahap Evaluasi Akhir

\begin{tabular}{|c|c|c|}
\hline \multirow{2}{*}{ Item Penilaian } & \multicolumn{2}{|c|}{ Hasil } \\
\hline & $\mathbf{Y a}$ & Tidak \\
\hline Kecelakaan fatal & $\sqrt{ }$ & \\
\hline Kebakaran besar & $\sqrt{ }$ & \\
\hline Kecelakaan sedang & $\sqrt{ }$ & \\
\hline Kebakaran sedang & $\sqrt{ }$ & \\
\hline $\begin{array}{l}\text { Pelaksanaan training internal } \\
\text { perusahaan }\end{array}$ & & $\sqrt{ }$ \\
\hline Pelaksanaan safety talk & $\sqrt{ }$ & \\
\hline Inspeksi K3 bersama & & $\sqrt{ }$ \\
\hline Kepatuhan pemakaian APD & & $\sqrt{ }$ \\
\hline Laporan mingguan aspek HSE & $\sqrt{ }$ & \\
\hline Kepatuhan terhadap rekomendasi & $\sqrt{ }$ & \\
\hline Tindak lanjut rekomendasi bersama & $\sqrt{ }$ & \\
\hline Total & 8 & 3 \\
\hline$\%$ & $72,7 \%$ & $27.3 \%$ \\
\hline
\end{tabular}

Berdasarkan Tabel 3 dapat dilihat bahwa PT.1 sebagai perusahaan kontraktor sipil yang bekerja sama PT. X Pasuruan pada tahapan evaluasi akhir terdapat 3 item penilaian tidak memenuhi syarat, sehingga nilai yang didapat $72,7 \%$, dimana nilai ini kurang dari $80 \%$ dan PT. 1 mendapatkan predikat buruk. PT.1 sebagai perusahaan kontraktor sipil yang bekerja sama PT. X Pasuruan tidak memenuhi persyaratan dan mendapatkan predikat buruk. Penilaian akhir ini masih sebatas penilaian sementara disebabkan karena pada saat peneliti melakukan penelitian pekerjaan di PT. X Pasuruan oleh PT. 1 sebagai perusahaan kontraktor sipil belum selesai dikerjakan.

\section{PEMBAHASAN}

\section{Tahapan Kegiatan Pra-Pekerjaan (Pre-Job Activity)}

Pada tahapan ini kontraktor/subkontraktor membuat SHE Plan sesuai dengan pekerjaan yang akan mereka telah disepakati oleh kedua belah pihak, di mana plan ini mencakup dalam target-target minimal accident yang harus dipenuhi, penggunaan APD dan program-program safety. Kecelakaan ini adalah suatu kejadian yang dapat terjadi tanpa disangka-sangka dan tidak dikehendaki karena ulah dari manusia itu sendiri dan keadaan lingkungan disekitarnya yang tidak aman, hal ini sesuai dengan pendapat menurut Suma'mur (2009), oleh sebab itu pengendalian risiko harus dilakukan sedini mungkin agar tidak menimbulkan kerugian yang besar. SHE plan yang telah dibuat oleh kontraktor/subkontraktor kemudian periksa dan disesuaikan dengan SHE plan yang telah disiapkan oleh planner perusahaan sesuai dengan tahapan penyusunan SMK3 pada OHSAS 18001 menurut Natsir (2007).

Pada tahapan pra-pelaksanaan pekerjaan ini, kontraktor/subkontraktor melakukan kick of meeting dengan sejumlah pihak PT. X Pasuruan (user, planner, pengawas pekerjaan dan safety), apabila planning yang telah dibuat tersebut belum seperti yang diharapkan maka kontraktor/subkontraktor diharuskan memperbaiki SHE plan lagi saat kick of meeting, dan ditandatangani oleh pihak kontraktor/ subkontraktor dan pihak PT. X Pasuruan.

Kontraktor/subkontraktor yang ada dalam tahapan pra pelaksana pekerjaan yang telah mendapatkan project PT. X Pasuruan, harus ikut serta dalam melakukan kick of meeting bersama pihak PT. X Pasuruan (user, planner, pengawas pekerjaan dan safety). Pada saat kick of meeting membahas hal-hal yang akan yang dilihat dari hasil SHE Plan, JSA dan analisis risiko yang telah di buat oleh kontraktor/subkontraktor. Pembahasan dari hasil job safety analysis dan hasil SHE Plan ini berguna untuk dapat menilai apakah penjelasan-penjelasan mengenai lingkup kerja yang dimulai dari rencana kerja yang merupakan tahapan awal pekerjaan sampai dengan tahapan akhir pekerjaan, kemudian untuk mengetahui risiko-risiko bahaya apa saja yang berpotensial dapat terjadi saat berlangsungnya pekerjaan, kemudian pengendalian apa saja yang dapat dilakukan dan alat pelindung diri apa saja yang disediakan oleh perusahaan, karena menurut Bird (2012), usaha pencegahan kecelakaan kerja dapat berhasil mencapai target apabila manajemen keselamatan dan kesehatan kerja perusahaan tersebut juga baik. Semua ini akan dibahas dalam kick of meeting. Pada saat kick of meeting, pihak PT. X Pasuruan juga akan mengajak kontraktor untuk melihat tempat project pelaksanaan pekerjaan yang akan dilakukan pekerjaan.

Pada kick of meeting ini akan masuk dalam SHE Plan yang dibuat oleh kontraktor/subkontraktor. SHE Plan ini mencakup safety meeting yang akan dilakukan, first aid yang akan dilakukan bila terjadi kecelakaan, pengumpulan laporan pekerjaan selama pekerjaan berlangsung, serta persentase yang didapat dari aspek safety pemakaian alat pelindung diri oleh masing-masing pekerja. SHE Plan kontraktor/ 
subkontraktor ini kemudian dicocokkan dengan SHE plan yang disiapkan oleh planner perusahaan. Pihak PT. X Pasuruan telah memberikan pengertian dengan tegas dan jelas, apabila terdapat kesenjangan antara SHE Plan yang dibuat oleh kontraktor/subkontraktor dengan SHE Plan yang dibuat planner, oleh sebab itu kontraktor/subkontraktor diharapkan untuk memperbaiki SHE Plan hingga sesuai dengan planner. Setelah SHE plan tersebut cocok dan disetujui oleh pihak PT. X Pasuruan, setelah itu kontraktor/subkontraktor akan menandatangani kontrak yang telah dipersiapkan, dalam kontrak ini harus ditandatangani oleh kedua belah pihak.

Informasi yang diberikan pada saat kick of meeting kepada kontraktor/subkontraktor secara jelas. SHE Plan yang ada juga harus di periksa dengan teliti, karena SHE Plan tersebut merupakan kunci utama penilaian kinerja kontraktor/ subkontraktor pada saat pekerjaan berlangsung, hal ini dapat mempengaruhi budaya kerja para pekerja, sehingga dapat diketahui apakah kontraktor/ subkontrakto dapat menerapkan budaya kerja yang aman bagi perusahaan PT. X Pasuruan. Pada kegiatan ini sesuai dengan isi kontrak tentang penyusunan dan perawatan perencanaan prosedur persyaratan keselamatan dan kesehatan kerja bagi kontraktor dan para pekerja yang ada di perusahaan (ILO, 2001).

SHE Plan yang ada ini dilakukan agar dapat memenuhi sistem management keselamatan dan kesehatan kerja berdasarkan OHSAS 18001: 2007 dan PP RI No. 50 Tahun 2012 di mana Occupational Health and Safety Management System atau dikenal sebagai Sistem Manajemen Kesehatan dan Keselamatan Kerja adalah suatu bagian dari sistem manajemen yang digunakan untuk membangun dan melakukan implementasi kebijakan K3 dan mengelola risiko K3 yang ada agar dapat menciptakan tempat kerja yang aman, efisien dan produktif bagi pekerja yang ada di sekitarnya.

\section{Tahapan Pelaksanaan Pekerjaan (Work in Progress)}

Menurut Rasjid (1992), tahapan pelaksanaan pekerjaan ini adalah dimana terdapat kegiatan yang dilakukan selama pekerjaan berlangsung sesuai dengan kesepakatan kedua belah pihak terutama dalam menerapkan sistem keselamatan dan kesehatan kerja, sehingga dalam tahapan ini kontraktor/subkontraktor harus melakukan upaya pencegahan kecelakaan kerja dalam setiap langkah kerjanya sesuai dengan sifat dan jenis bahaya yang ada selama pelaksanaan pekerjaannya berlangsung hal serupa juga dijelaskan oleh Restuputri (2015). Kontraktor/subkontraktor melaksanakan pekerjaan sesuai dengan rentang waktu yang telah disepakati oleh PT. X Pasuruan, selama pekerjaan berlangsung PT. X dapat melakukan penilaian pekerjaan yang dilakukan pada minggu ke dua saat pekerjaan sedang berlangsung, setelah itu para kontraktor/ subkontraktor dapat dinilai secara berkala selama proses pekerjaan berlangsung. Tolak ukur dalam penilaian pelaksanaan pekerjaan ini adalah target SHE Plan yang telah disepakati oleh pihak PT. X Pasuruan dengan pihak kontraktor PT. 1.

Tahapan pelaksanaan pekerjaan tetap menerapkan sistem manajemen supaya perusahaan dapat mengetahui kinerja kontraktor/subkontraktor yang baik dan sesuai dengan peraturan yang ada mengenai aspek-aspek yang saling berhubungan di perusahaan, sehingga perusahaan dapat menjamin keselamatan dan kesehatan kerja kontraktor/ subkontraktor hal ini sesuai dengan pendapat (Ahyadi, 2009), melindungi fasilitas serta aset perusahaan melalui pengawasan yang sistematis dengan melakukan pengendalian sesegera mungkin terhadap penyimpangan-penyimpangan yang terjadi. Selama tahapan pekerjaan berlangsung kontraktor/ subkontraktor harus menyerahkan laporan rutin yang sesuai dengan SHE Plan yang ada, selain itu juga manajemen PT. X melakukan penilaian dengan menggunakan lembar observasi kontraktor sipil yang dilakukan sesuai jadwal yang telah dibuat. Pada tahapan pelaksanaan pekerjaan ini telah sesuai dengan Permen 05/MEN/1996 tentang elemen SMK3 yaitu dalam pemeliharaan komitmen kebijakan, peninjauan ulang perancangan dan kontrak pengendalian perancangan, pengendalian dokumen, standart pemantauan kegiatan, pengembangan dan pemeliharaan komitmen kebijakan, strategi pendokumentasian, keamanan bekerja berdasarkan SMK3.

\section{Tahapan Evaluasi Akhir}

Tahapan evaluasi akhir bertujuan untuk mengevaluasi kinerja kontraktor tahapan ini akan dijadikan bahan pertimbangan bagi PT. X Pasuruan untuk membuat keputusan apakah perusahaan akan melanjutkan kerja sama atau tidak, serta diharapkan dapat meningkatkan program di perusahaan terutama tentang CSMS, apabila kontraktor/subkontraktor mendapatkan nilai yang baik pada tahapan evaluasi 
akhir ini, maka perusahaan akan mengundang kembali kontraktor/subkontraktor untuk tender pekerjaan berikutnya.

Pada tahapan ini belum didapatkan hasil penilaian akhir, hal ini disebabkan pada saat proses pengambilan data tersebut proses pekerjaan belum berakhir, sehingga pihak manajemen PT. $\mathrm{X}$ Pasuruan tersebut belum mengeluarkan hasil dari tahap penilaian akhir. Data didapatkan dari wawancara dengan pihak PT. X Pasuruan untuk dapat mendukung hasil dari penelitian ini.

Pada wawancara yang dilakukan, menurut pihak PT. X Pasuruan penilaian akhir mengacu pada penilaian sementara yang telah dilakukan dan hasil dari penilaian sementara ini bisa saja berubah apabila pihak kontraktor/subkontraktor melakukan perbaikan pada hasil penilaian yang rendah. Sesuai dengan hasil analisis, penilaian yang rendah seperti penggunaan APD, kedisiplinan selama proses pekerjaan berlangsung dan penggunaan alat kerja yang sesuai dengan kebutuhan dapat diperbaiki dengan mematuhi proses pekerjaan yang sedang berlangsung, meningkatkan kedisiplinan dan penggunaan alat kerja sesuai kebutuhan, begitu juga dalam penggunaan APD, setelah para kontraktor tersebut dapat melengkapi APD mereka, maka hasil penilaian dalam penggunaan APD tersebut dapat meningkat, namun dalam penilaian terjadinya kecelakaan dan kebakaran (flash), hal ini tidak sesuai dengan pendapat menurut Mangkunegara (2001), karena tidak memenuhi peraturan yang dibuat oleh perusahaan dalam meningkatkan keselamatan dan kesehatan kerja, sehingga pihak PT. X Pasuruan mengatakan hasil penilaian tidak akan berubah mengingat dalam hal tersebut telah terjadi dan hasil penilaian akan menurun dengan sendirinya dan apabila hal tersebut tidak berdampak buruk dan luas, pihak PT.X Pasuruan akan memberikan intervensi kepada kontraktor/subkontraktor tentang cara pengendalian terhadap bahaya tersebut dan risiko bahaya lainnya yang mungkin akan terjadi.

\section{SIMPULAN}

Pelaksanaan tahapan pra-pekerjaan (pre-job activity) sejauh ini implementasinya sudah mengacu dengan tata kerja pada pedoman CSMS yang telah dibuat oleh PT. X Pasuruan, seperti melakukan kock of meeting dengan membahas SHE plan dan membandingkan dengan rencana yang dibuat oleh planner, sehingga PT.1 dapat mencegah dan mengendalikan bahaya apabila terjadi di sekitar tempat kerjanya.

Tahapan pelaksanaan pekerjaan (work in progress) dilakukan sesuai dengan pedoman CSMS PT. X Pasuruan, namun terdapat beberapa hambatan yang membuat skor pada tahap pelaksanaan ini menjadi buruk, hal ini terjadi karena kedisiplinan dalam tim kurang baik. Hasil penilaian yang buruk tersebut sesegera mungkin dilakukan tindakan oleh PT.X Pasuruan dengan memberikan intervensiintervensi terhadap nilai yang buruk tersebut, selain itu juga PT.X Pasuruan perlu untuk mengadakan training bagi para pekerja maupun kontraktor/ subkontraktor dalam pengendalian bahaya dan kedisiplinan dalam menggunakan alat pelindung diri.

Tahapan evaluasi akhir ini belum didapatkan hasil penilaian akhir, hal ini disebabkan pada saat proses pengambilan data tersebut proses pekerjaan belum berakhir, sehingga belum mendapatkan data yang dapat mendukung analisa tahapan evaluasi akhir, karena hanya mendapatkan data dari proses wawancara terhadap pihak PT. X Pasuruan. Berdasarkan hasil wawancara, pihak manajemen PT. $\mathrm{X}$ Pasuruan masih belum dapat bersikap tegas dan konsisten dalam memberikan sanksi bagi kontraktor/ subkontraktor yang melanggar aturan dan melakukan tindakan yang berisiko bahaya bagi dirinya sendiri maupun orang di sekitarnya.

Risiko bahaya pada kontraktor/subkontraktor sipil di tempat kerjanya dapat dicegah seminimal mungkin, hal ini karena terdapat sistem manajemen yang baik pada perusahaan. Perusahaan patuh dalam menjalankan program CSMS yang mengatur tentang sistem manajemen kesehatan dan keselamatan kerja.

\section{DAFTAR PUSTAKA}

Ahyadi, H. 2009. Analisis Identifikasi Bahaya pada Proses Produksi PT.X dengan Metode Risk Assesment. Jurnal PASTI. Jakarta: Universitas Muhammadiyah. Vol. IX, No. 1: 46-60.

Bird, F. E. 1989. Management Guide to Loss Control. Georgia: Institute Publishing Loganville.

International Labours Office (ILO). 2001. Guideline on Occupational Safety Management System. Geneva: LLO-OSH.

Jamsostek. 2012. Perlindungan Jamsostek Kasus Kecelakaan Kerja Masih Tergolong Tinggi. www. jamsostek.co.id/content/news.php?id=212S. (Sitasi pada tanggal 15 September 2016). 
Lukiatsinto, R. 2014. Penerapan CSMS Sebagai Upaya Pencegahan Kecelakaan Kerja. The Indonesian Journal of Occupational Safety and Health. Surabaya: Universitas Airlangga. Vol. 3, No. 2 Jul-Des 2014: 192-200.

Mangkunegara, A. A. 2001. Manajemen Sumber Daya Manusia. Bandung: PT. Remaja Rosdakarya.

Natsir, M. 2007. Occupational and Health Safety Assessment Series, OHS Safety Management System Requirements. Jakarta: Ghalia Indonesia.

Nitya, R. S. 2010. Hubungan Pengetahuan, Keterlibatan Kerja dan Kepuasan Kerja dengan Praktik disiplin dalam Penerapan Contractor Safety Management System pada Perusahaan X. Jurnal PASTI. Malang: Universitas Muhammadiyah. Vol. XI, No. 1: 37-53.

Notoatmodjo, S. 2010. Metodologi Penelitian Kesehatan. Jakarta: Rineka Cipta.

Peraturan Menteri Tenaga Kerja Nomor 05/MEN/1996 Tentang Sistem Manajemen Keselamatan dan Kesehatan Kerja (SMK3).

Peraturan Pemerintah Republik Indonesia No. 50 Tahun 2012. Tentang Penerapan Sistem Manajemen Keselamatan dan Kesehatan Kerja.

Ramli, S. 2009. Sistem Manajemen Keselamatan dan Kesehatan Kerja. Jakarta: Dian Rakyat.
Rasjid, R. 1992. Pencegahan Kecelakaan dalam Indastri. Surabaya: Lokakarya.

Restuputri, D.P. 2015. Analisis Kecelakaan Kerja dengan Menggunakan Metode Hazard And Operability Study (HAZOP). Jurnal Ilmu Teknik Industri. Malang: Universitas Muhammadiyah. Vol. 14, No 1:24-35.

Sahab, S. 1997. Teknik Manajemen Keselamatan dan Kesehatan Kerja. Jakarta: PT. Bina Sumber Daya Manusia.

Setyawan, A. 1997. Teknik Manajemen Keselamatan dan Kesehatan Kerja. Jakarta: PT. Bina Sumber Daya Manusia.

Sucofindo. 2011. Konsultasi Pengembangan Sistem Manajemen Keselamatan Kontraktor. www. sucofindo.co.id (Sitasi pada tanggal 15 September 2016).

Sugandi, D. 2003. Keselamatan Kerja dan Pencegahan Kecelakaan Kerja. Bandung: PT. Remaja Grafindo Persada.

Sulistyawati, D. 2013. Evaluasi Penerapan Sistem Manajemen K3 dan Peningkatan Fasilitas PT. Trakindo. Jurnal Sipil Statistik. Manado: Universitas Sam Ratulangi. Vol. 1, No. 5: 318-327.

Suma'mur. 2009. Keselamatan Kerja dan Pencegahan Kecelakaan Kerja. Jakarta: CV. Haji Masagung. 